\title{
Measuring surface waviness during plunge-cut grinding
}

\section{Pomiar falistości powierzchni w procesie szlifowania wgłębnego}

\author{
JAN BUREK \\ PAWEK KUBIK \\ ROBERT BABIARZ \\ PAWE SUŁKOWICZ *
}

\begin{abstract}
A method for measure a cylindrical surface waviness during grinding online has been presented. Three inductive sensors have been used in the measurement system. Thanks for that possible is mathematical data analyse which exclude a vibration influence on a measure waviness value.
\end{abstract}

KEYWORDS: grinding, surface waviness, inductive sensors

The main reason for the formation of waviness of the cylindrical surface of an object in the grinding process is the non-balancing of the grinding wheel, which occurs due to uneven wear of its work surface during processing [1]. For this reason, automatic wheel balancing systems are introduced during grinding, mounted on its spindle $[2,3]$. Due to the relatively high cost of these systems, as well as the impossibility of flawless balancing of the grinding wheel, especially in the case of grinding wheels with large diameters, these systems have not found widespread use in industrial practice.

The currently produced CNC grinders allow for the correction of the setting parameters during the grinding process [4]. They are also equipped with arrangements for checking the active diameter of the object, which makes it possible to eliminate the influence of radial wear on the dimensional accuracy of the object [5].

It has been proposed that the active control system, after retrofitting three inductive sensors, should be used to measure the waviness during the grinding process, which can then be used to control the rotation ratio of the grinding wheel to the rotational speed of the object. In this way, it is possible to reduce the amplitude of the surface waveform in real time.

The aim of the research was to check the possibility of using inductive sensors to measure waviness during grinding in real time.

\section{Surface waviness measurement method}

The tested method of measuring the surface waveform during grinding relies on the use of three inductive sensors 1,2 and 3 . This allows to eliminate the influence of

\footnotetext{
* Dr hab. inż. Jan Burek prof. PRz (jburek@prz.edu.pl), mgr inż. Paweł Kubik (p.kubik@prz.edu.pl), dr inż. Robert Babiarz (robertb@prz.edu.pl), mgr. inż. Paweł Sułkowicz (sulkowicz@prz.edu.pl) - Katedra Technik Wytwarzania i Automatyzacji, Wydział Budowy Maszyn i Lotnictwa Politechniki Rzeszowskiej
}

vibrations on the measured signal by using mathematical methods to calculate the displacement of the center of rotation of the measured object. The schematic of the measurement system is shown in fig. 1.

The base of the system is not the workpiece, but the body of the active control system. Hence, the oscillations of the workpiece are detected by inductive sensors as a change in the distance between the sensor and the workpiece. This leads to changes in the distance between the sensor and the cylindrical surface, which causes measurement errors in the surface profile. Therefore, it is necessary to eliminate vibrations in a mathematical way.

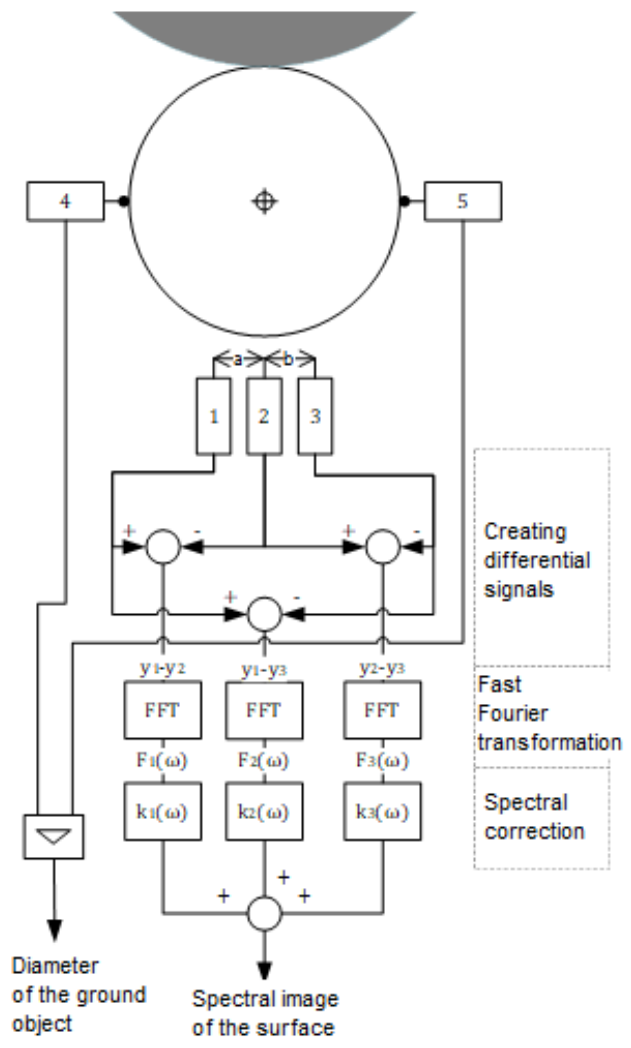

Fig. 1. Scheme of the surface wave measuring system during grinding: 1,2, 3 - inductive sensors used to measure the waviness of the object; 4, 5- active item diameter control sensors; $y_{1}, y_{2}, y_{3}-$ measurement signals from sensors 1, 2, 3; FFT - fast Fourier transformation; $k_{1}, k_{2}, k_{3}$ - correction factors 
If the profile of the surface profile is described as a sinusoidal modulation with the equation: $A \sin \left(\omega t+\varphi_{A}\right)$, and the center of the workpiece is moved parallel to the inductive sensor with the equation: $B \sin \left(\omega t+\varphi_{B}\right)$, then the measured values can be described as: $C \sin (\omega t+\psi)$.

The oscillation of the object is mainly due to the surface waveform, hence the vibrations of the wave-causing whee have the same frequency as the vibrations of the center of rotation of the object. Due to the overlapping of waves of the same frequency, the signal components coming from vibrations can not be removed without additional information. The influence of vibrations on the measurement of waviness is presented in fig. 2 .

a)

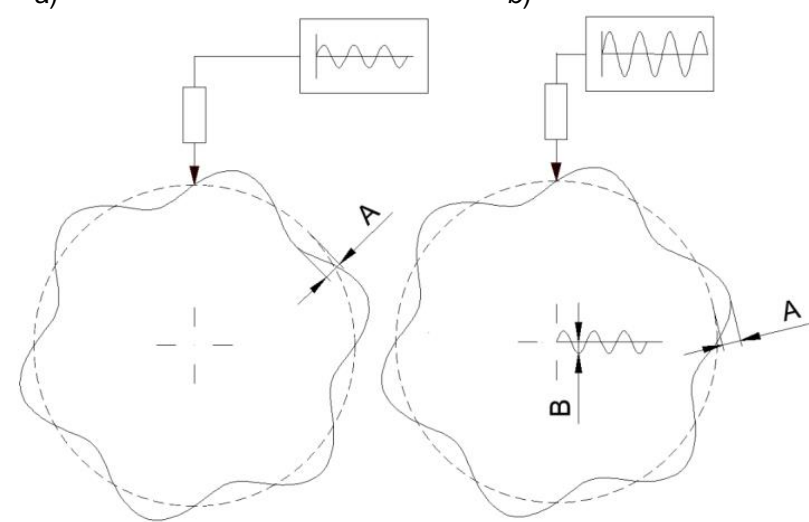

Fig. 2. Effect of object vibrations on the measurement of waviness: a) measurement without vibrations, b) measurement including vibrations

Therefore, at least two sensors are used to eliminate the vibration components of the object from the measurement signal - as in fig. 3 .

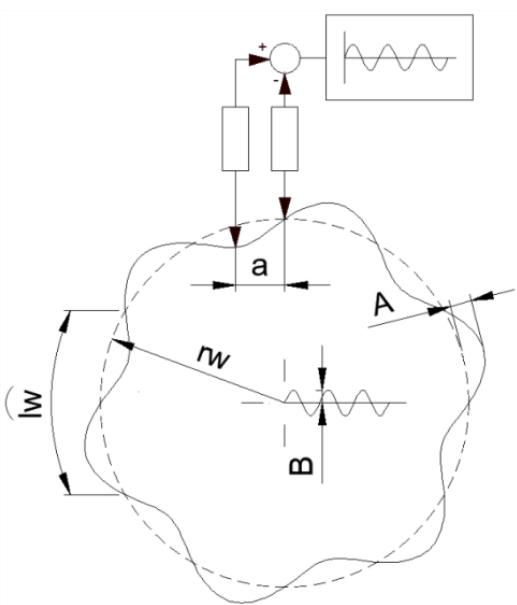

Fig. 3. Corrugation measurement using two sensors

After using two sensors, the output signal is calculated according to the equation:

$$
\begin{aligned}
y_{1}(t)-y_{2}(t)= & \left(A \sin \left(\omega t+\varphi_{A}\right)+B \sin \left(\omega t+\varphi_{B}\right)\right) \\
& -\left(\left(A \sin \left(a x+\varphi_{A}+\varphi_{T}\right)\right.\right. \\
& \left.\left.+B \sin \left(\omega t+\varphi_{B}\right)\right)\right) \\
& =C \sin (\omega t+\psi)
\end{aligned}
$$

where:

$$
\begin{aligned}
C & =\sqrt{2 A^{2}+2 A^{2} \cos \left(\left(\varphi_{A}+\varphi_{T}+2 \pi\right)-q_{A}\right)} \\
\psi & =\tan ^{-1} \frac{A \sin \left(\varphi_{A}+\varphi_{T}\right)+A \sin \left(\varphi_{A}+\varphi_{T}+2 \pi\right)}{A \cos \left(\varphi_{A}+\varphi_{T}\right)+A \cos \left(\varphi_{A}+\varphi_{T}+2 \pi\right)}
\end{aligned}
$$

where:

$A, B, C$ - amplitude of waveform,

$\varphi_{T}=\frac{a w}{2 \pi r_{w}}$

- $a-$ distance between sensors,

- $\quad w$ - number of waves,

- $r_{\mathrm{w}}$ - radius of the workpiece,

$\varphi_{\mathrm{A}}, \varphi_{\mathrm{B}}, \varphi_{\mathrm{C}}-$ phase shift of waviness.

Using equations (2) and (3), you can calculate the amplitude of the waveform according to the equation:

$$
A=\frac{C}{\sqrt{2\left(1-\cos \varphi_{T}\right)}}
$$

The equation (4) is unlabeled if $\varphi_{T}=1$. This is the case when the distance $a$ is the total multiple of the wavelength $I_{w}$. The differential signal then assumes a value of 0 regardless of the amplitude of the waviness.

In order to eliminate uncertainty, which occurs when the distance between the sensors and the wave length overlaps, the three sensors are arranged in different distances. The measurement signals from $y_{1}, y_{2}, y_{3}$ come from these sensors, which after amplification are transmitted to the signal processing block.

If three sensors are used, indeterminacy occurs when the sum of the three distances between the sensors is an integral multiple of the wavelength. Since the distance between sensor 1 and 3 is the sum of distances between sensors 1-2, 2-3, then the sum of all sensor distances can be written as: $2(a+b)$. From this it follows that in this method, due to the proper selection of the distance of the sensors, it is possible to ensure that the uncertainty occurs for a wavelength that is out of the frequency range of the waviness.

To determine the spectral image of the surface waveform, calculate the difference of signals: $y_{1}-y_{2}, y_{1}-$ $y_{3}, y_{2}-y_{3}$. Next, the difference is chosen for which the correction factor $k(\omega)$ is the smallest. The resulting signal is distributed using a Fourier series:

$$
u(t)=\frac{U_{0}}{2}+\sum_{n-1}^{\infty} U_{n} \sin n \omega+\sum_{n-1}^{\infty} V_{n} \cos n \omega
$$

where:

$$
\begin{aligned}
& U_{n}=\frac{1}{\pi} \int_{0}^{2 \pi} f(\omega) \sin n \omega d \omega \\
& V_{n}=\frac{1}{\pi} \int_{0}^{2 \pi} f(\omega) \cos n \omega d \omega
\end{aligned}
$$

The constant component of the amplitude $U_{0}$ is omitted and the amplitudes of $U_{\mathrm{n}}$ and $V_{\mathrm{n}}$ of the harmonic components for the difference signal are determined. The harmonic amplitudes of the differential signal are calculated as the lengths of $U_{n}$ and $V_{n}$ vectors according to the order:

$$
C_{n}=\sqrt{U_{n}{ }^{2}+V_{n}{ }^{2}}
$$

The last step is to multiply the value of $c_{n}$ by the value of correction factor $k(\omega)$. In this way, the surface waviness spectrum is obtained. 


\section{Research stand}

The test stand was built on the basis of the Geibel \& Hotz RS600C shaft grinder (fig. 4). A set of three inductive sensors from Tesa GT21 was installed in the active part diameter control system, from which the signals are transmitted to the amplifier, measuring card and computer.

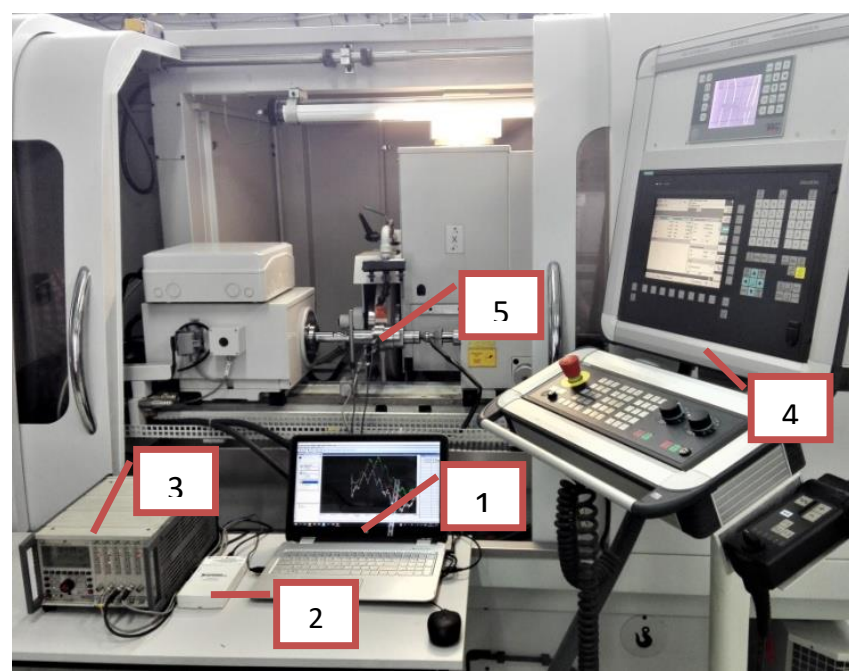

Fig. 4. Test stand: 1 - computer, 2 - measurement card 3-amplifier, 4-control panel, 5-inductive sensors

Sensors with a measuring range of $\pm 2 \mathrm{~mm}$, a maximum measurement error of $0.2+(3 L 3) \mu \mathrm{m}$, hysteresis of $0.01 \mu \mathrm{m}$ and a maximum frequency of $60 \mathrm{~Hz}$ were used [6].

\section{Measurements}

The corrugation was measured for three speeds of machined parts: 4,8 and $16 \mathrm{rpm}$. The applied rotational speeds of the object during the measurement result from the maximum measurement frequency of the sensors.

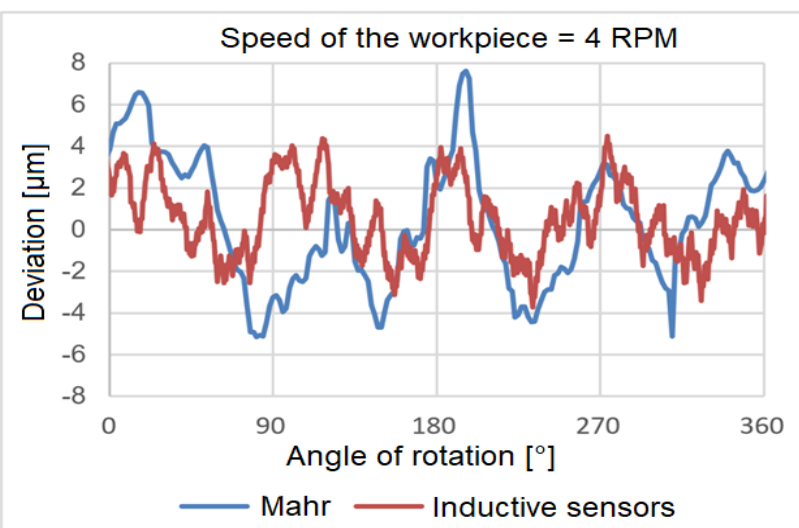

Fig. 5. Measured surface profile at a rotational speed of $4 \mathrm{rpm}$

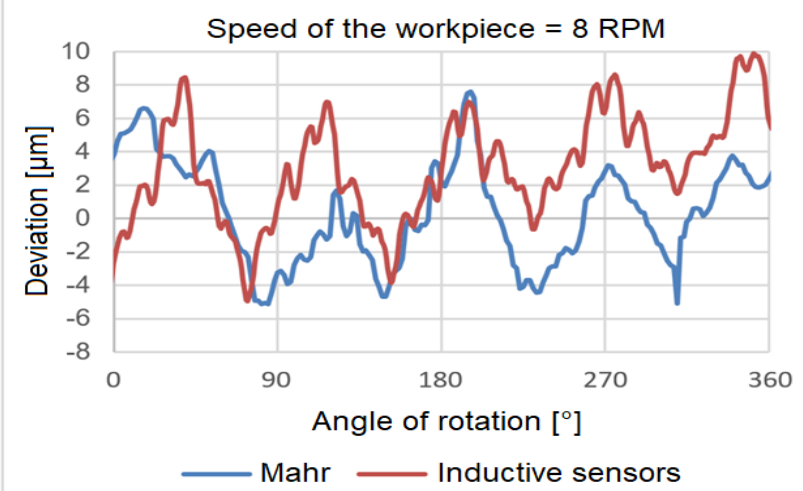

Fig. 6. Measured surface profile at a rotational speed of $8 \mathrm{rev} / \mathrm{min}$

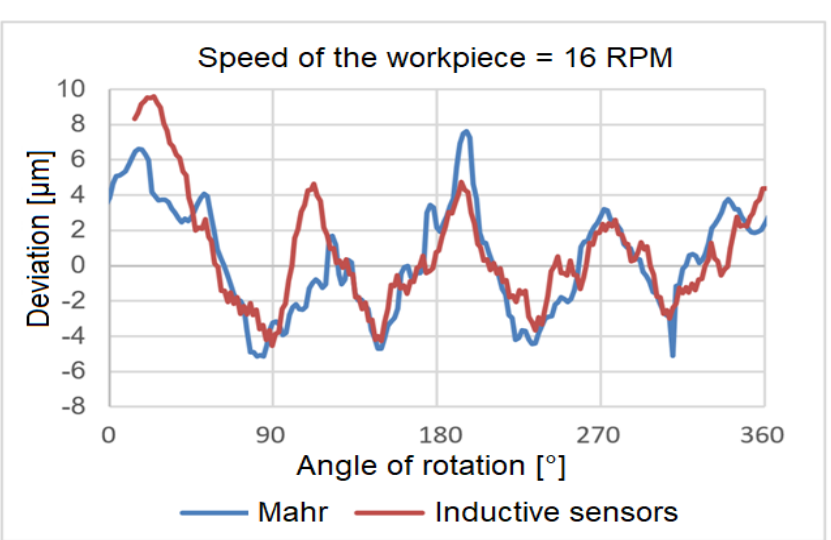

Fig. 7. Measured surface profile at a rotational speed of $16 \mathrm{rpm}$

During the measurement, sampling at $100 \mathrm{~Hz}$ was used. At the same time, signals from three inductive sensors were recorded. The results were digitally processed to obtain the actual surface profile.

As reference data, the measurement was made on a universal machine for the evaluation of the workpiece MarForm MMQ 400. The results of the registered profiles of undulations are presented in figs. 5-7. The surface profile measured with the Mahr device is marked in blue. Red color - profile measured with inductive sensors.

\section{Conclusions}

The use of three inductive sensors allows you to measure surface waviness during grinding. Due to the low limit frequency of inductive sensors measurement, there are significant discrepancies between the MarForm MMQ 400 profiles and inductive sensors in places where there is a significant change in wave height over a short measuring section.

There are slight discrepancies in the frequency of the measured waves. They can result from differences between the actual and assumed in the calculations the rotational speed of the workpiece. The maximum difference in the results between the MarForm device and induction sensors does not exceed $8 \mu \mathrm{m}$.

It should be noted that due to the phase shift caused by the position of the sensors at a certain distance from each other, in order to be able to map the surface in the full angle range, the measurement must be made for rotation greater than $360^{\circ}$.

\section{REFERENCES}

1. Fotch M. "Abbildung von Maschinenschwingungen auf die WerkstLcoberflocheWerkstükoberflöche beim Aussenrundschleifen". Industrie Anzeiger. 73 (1987): pp. 30-31.

2. Wójtowicz J. „Automatyczne wyważanie ściernic i diagnozowanie szlifierek”. Mechanik. 8-9 (1999): pp. 579-581.

3. Liu C., Liu W., Mei C.L. „The design wheel balancing control system ans control software". AER-Advances in Engineering Research. 17 (2015): pp. 1095-1098.

4. Burek J. „Pomiar parametrów procesu szlifowania dla realizacji sterowania adaptacyjnego (AC)". Pomiary Automatyka Kontrola. 2 (1997): pp. 36-38.

5. Marposs: Czujniki elektroniczne. Katalog główny.

6. Tesa: "Elctronic Length Measuring Equimpents".

Translation of scientific articles, their computer composition and publishing them on the website www.mechanik.media.pl by original articles in Polish is a task financed from the funds of the Ministry of Science and Higher Education designated for dissemination of science.

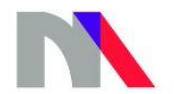

Ministry of Science and Higher Education

Republic of Poland 